\title{
Povos indígenas da Amazônia: do caminho da canoa à ressignificação das culturas e línguas ${ }^{1}$
}

\author{
Amazonia's indigenous peoples: from the canoe path to \\ the reframing of cultures and languages
}

\author{
Ademar dos Santos Lima² \\ Rosineide Magalhães de Sousa²
}

DOI: http://dx.doi.org/10.20435/tellus.vi44.726

\begin{abstract}
Resumo: Este artigo traz um relato sobre as experiências dos povos indígenas da Amazônia na construção e uso de embarcações bũgu (casco de tronco de árvore) e igara (canoa de madeira) desde a chegada das primeiras civilizações na região amazônica, assim como a evolução que ocorreu na construção de embarcações de grande porte como igarité (barco) e igaritéasu (navio) com a chegada dos europeus, e posteriormente, se faz uma breve analogia entre tronco da árvore e tronco linguístico relacionando aos povos indígenas que perderam suas línguas maternas e adotaram como língua de comunicação o Nheengatu. A metodologia utilizada foi de abordagem etnográfica. O estudo faz parte do projeto de doutorado em andamento: A situação sociolinguística e de letramento em nheengatu dos alunos e professores das escolas indígenas do município de Manaus, cujo objetivo nesse trabalho foi de contextualizar os aspectos socioculturais à situação sociolinguística desses povos a partir de suas vivências e experiências do dia a dia ao processo de aquisição e uso da língua Nheengatu, fazendo uma breve analogia entre o termo tronco da árvore e o termo tronco linguístico. O estudo constatou, a partir do contexto sociocultural, que os povos indígenas constroem e usam o bũgu desde suas primeiras gerações, o qual faz parte da cultura da população amazônica e é utilizado como o principal meio de transporte nos rios ygarapé (caminho da canoa) na Amazônia, e no contexto sociolinguístico, averiguamos que os povos Baré, Mura e Warekena perderam suas primeiras línguas maternas e assimilaram a língua Nheengatu e o português brasileiro.
\end{abstract}

Palavras-chave: sociolinguística; cultura amazônica; tronco linguístico; ressignificação.

1 Este artigo faz parte da pesquisa do projeto de doutorado intitulado A situação sociolinguística e de letramento em língua nheengatu dos alunos e professores das escolas indígenas do município de Manaus, Amazonas, que se insere no projeto do Grupo de Pesquisa (Socio) Linguística, Letramentos Múltiplos e Educação (SOLEDUC), certificado pelo CNPq.

2 Universidade de Brasília (UnB), Brasília-DF, Brasil. 


\begin{abstract}
This paper reports on the experiences of indigenous peoples in Amazonia about construction and use of bũgu (tree trunk hull) and igara (wooden canoe) vessels since the arrival of the first civilizations in the amazon region and after these, the evolution which occurred in the construction of large vessels such as igarité (boat) and igaritéasu (ship) with the arrival of Europeans. Later, we did a brief analogy between the tree trunk and the linguistic trunk relating to the indigenous peoples who lost their mother tongues and assimilated Nheengatu as an ethnic language. The methodologies used was ethnography. This research is part of the ongoing doctoral project: The sociolinguistic and literacy situation in Nheengatu of indigenous students and teachers from municipal schools in Manaus, whose objective of this work was to contextualize the socio-cultural aspects to the sociolinguistic situation of these peoples from their experiences from day by day experiences to the process of acquisition and use of the Nheengatu language making a brief analogy between the term tree trunk and the term linguistic trunk. The study found based on the socio-cultural context that indigenous peoples have built and used the bũgu since their early generations, which is part of their culture and is used as the main means of transport in the rivers ygarapé (canoe path) of the Amazonia, and in the sociolinguistic context we found that the Baré, Mura and Warekena peoples lost their first mother tongues and assimilated the Nheengatu language and the brazilian portuguese language.
\end{abstract}

Keywords: sociolinguistics; amazonian culture; linguistic trunk; reframing.

\title{
1 INTRODUÇÃO
}

Os povos da Amazônia são civilizações autóctones ${ }^{3}$, assim como as línguas deles, originárias do continente da América e faladas na região amazônica por aproximadamente 230 mil falantes, divididas em dois grandes troncos linguísticos e em mais de trinta famílias linguísticas distribuídas em aproximadamente 180 etnias, povos indígenas (IBGE, s.d.).

Os traços socioculturais dos povos indígenas da Amazônia estão intrinsicamente imbricados com a flora amazônica, e entre os elementos principais de relação entre ambos está a floresta com suas árvores altaneiras que, a partir de seus troncos produz-se canoas, os principais meios de locomoção da população dessa região. A flora amazônica é nomeada em língua geral, o Nheengatu, idioma falado atualmente pelos povos Arapaso, Baniwa, Baré, Mura, Warekena e outros (RODRIGUES, 2013).

Os primeiros meios de transportes fluviais da Amazônia são conhecidos como bũgu (casco de tronco de árvore) e igara (canoa de madeira) em Nheengatu,

3 Autóctones são pessoas naturais do país ou região em que habitam como aborígenes e indígenas. 
os quais são construídos a partir da seleção de tronos das melhores árvores como castanheira bertholletia excelsa, itaúba mezilaurus itauba, loureiro laurus nobilis, cedro cedrus, jacareúba calophyllum brasiliense, angelim dinizia excelsa ducke, cupiúba goupia glabra aubi, andiroba carapa guianensis, paracuúba dimorphandra macrostachya e sucupira pterodon pubescens.

De acordo com historiadores como Németh (2011), o casco de tronco de árvore como é conhecido em português brasileiro (PB), foi uma das embarcações mais utilizadas para transporte de pessoas pelos rios e igarapés da Amazônia no período colonial, e até hoje ainda há indígenas e caboclos que utilizam o casco para pescar, caçar, transportar mantimentos e utensílios.

Sobre o uso desse tipo de embarcação, há o relato de Cristovão Colombo em seu diário de viagem de 26 de outubro de 1492, que ao chegar pela primeira vez em terras do Continente Americano relatou que os indígenas andavam de canoas almadías.

Não há relatos de quando surgiu o primeiro casco bũgu na Amazônia, mas se acredita que foi desde a primeira povoação ameríndia da região, pois o mais antigo barco que se tem notícia no mundo é a canoa de Pesse, uma canoa de tronco de pinheiro Pinus sylvestris escavada, construída entre os séculos 8.200 e 7.510 a.C. Essa canoa está no museu Drents, na cidade holandesa de Assen, Países Baixos.

Na Amazônia, o bũgu, casco de tronco de árvore evoluiu, e passou a se chamar canoa. A mudança não ocorreu só no nome, mas também no design, a canoa atual é composta de várias partes de madeira como: tábua, caibro, quilha, prego, parafuso e betume para calafeto. Diferente do casco que é feito de um único tronco de árvore e não necessita de betume, nem de prego e parafuso.

Certamente que houve uma grande evolução desde o primeiro casco até chegar à era das canoas. Assunto que trataremos no capítulo da evolução do casco de tronco de madeira.

Entretanto, o foco principal do estudo é a analogia entre o tronco da árvore e o tronco linguístico relacionado aos povos indígenas Baré, Mura e Warekena que perderam suas línguas maternas ${ }^{4}$ e adotaram o Nheengatu como língua étnica e,

4 Língua materna refere-se à primeira língua (L1) e inclui um conjunto de termos que se sobrepõem para designar a língua usada por um indivíduo desde o nascimento (BAGNO, 2017, p. 238). 
como assunto secundário, o contexto sociocultural das populações amazônicas na construção de embarcações.

As questões norteadoras foram: De que forma os povos amazônicos se reinventaram a partir do contato com o mundo ocidental e como se operou o processo de ressignificação dos troncos arbóreos e linguísticos no contexto sociocultural?

Assim, as asserções da pesquisa foram concebidas da seguinte forma: $O$ contexto sociocultural dos povos indígenas da Amazônia na construção e uso de embarcações como casco de tronco de árvore (bũgu) e de canoa de madeira (igara) desde a as primeiras civilizações ameríndias na região amazônica até a chegada dos colonizadores ocidentais;

A analogia entre o tronco da árvore e o tronco linguístico relacionado aos povos indígenas Baré, Mura e Warekena que perderem suas línguas maternas e adotaram o Nheengatu e o português;

A partir do contato com os colonizadores ocidentais, os povos indígenas ressignificaram suas culturas para dar conta de explicar seus modos de vidas socioculturais no contexto amazônico. Esse contato linguístico e cultural entre indígenas e europeus corroborou para uma grande mudança na cultura e línguas dos povos originários da Amazônia.

Acreditamos que ao respondermos estas questões, o estudo justifica-se, na medida em que os resultados da pesquisa contribuem para uma reflexão de como a ressignificação dos processos socioculturais e sociolinguísticos em uma outra língua levou aos povos indígenas Baré, Mura e Warekena a reinventarem suas identidades culturais e linguísticas.

Dessa forma, a pesquisa corrobora também para a compreensão do papel histórico-cultural da prática e uso da língua nheengatu no processo de construção social da identidade coletiva dos povos indígenas, moldado pelas práticas socioculturais e sociolinguísticas deles.

Desse modo, os objetivos deste estudo foram: Descrever as experiências dos povos indígenas da Amazônia na construção e uso de embarcações como casco de tronco de árvore (bũgu) e de canoa de madeira (igara) desde a as primeiras civilizações ameríndias na região amazônica até a chegada dos colonizadores ocidentais; 
Fazer uma breve analogia entre o tronco da árvore e o tronco linguístico relacionando aos povos indígenas Baré, Mura e Warekena que perderem suas línguas maternas e assimilaram o Nheengatu e o português;

Mostrar como os povos indígenas, a partir do contato com os colonizadores ocidentais ressignificaram suas culturas para dá conta de explicar seus modos de vidas socioculturais no contexto amazônico.

A pesquisa foi de abordagem etnográfica aplicada como técnica para a coleta e geração de dados da pesquisa. Inicialmente, foi realizada à revisão da literatura do tema abordado, por meio de levantamento e leitura da bibliografia referenciada neste trabalho, breve estudo etnográfico de figuras, imagens, iconográficos e textos históricos, e posteriormente foi feito o estudo descritivo, que foi a descrição dos dados coletados (gerados) na fase da etnografia (PAIVA, 2019, p. 79).

Desse modo, o estudo teve um alcance etnográfico relevante de conteúdo com foco na analogia entre o tronco da árvore e o tronco linguístico relacionado ao contexto da cultura dos povos indígenas que perderem suas línguas maternas e adotaram o Nheengatu e o português brasileiro, para ressignificarem suas essências identitárias e culturais, e assim se reinventarem para interagir com a cultura ocidental para dá conta de explicar seus modos de vidas socioculturais no contexto amazônico (GIL, 2006, p. 73).

O universo da pesquisa foi o estudo sobre os aspectos socioculturais e sociolinguísticos dos povos Baré, Mura e Warekena. A informação levantada na etnografia seguiu as recomendações dos dados pesquisados seguiu as recomendações de Tarallo (2003, p. 17-27) sobre a coleta (geração) de dados linguísticos e de Hymes (1972, p. 65), que propõe um modelo bastante conveniente, a etnografia da comunicação. Os dados foram coletados a partir de documentos e de levantamento etnográfico nas comunidades dos povos Baré, Mura e Warekena no estado do Amazonas.

Para melhor ilustrar o estudo de corpora deste trabalho, foram coletadas imagens (fotos) e elaboração de iconográficos, gráficos e tabelas com o objetivo de organizar, descrever e contextualizar os dados da pesquisa e, posteriormente o desenvolvimento das discussões.

Ao desenvolvermos o estudo, não só pretendemos apresentar as histórias da região amazônica, mas mostrar também as riquezas das diversidades culturais, 
linguísticas, tradições e peculiaridades dos povos da Amazônia. Essa região é considerada como a maior área de concentração de povos indígenas das américas (QUEIXALOS; RENAULT-LESCURE, 2000).

O artigo está estruturado a partir desta introdução inicial; da seção 2 que discute sobre a origem do casco de madeira; a seção 3 trata da ressignificação das experiências socioculturais; a seção 4 faz uma analogia da ressignificação dos troncos arbóreos e linguísticos; e finalmente a seção 5 traz as considerações finais.

\section{A ORIGEM DO CASCO DE MADEIRA/BŨGU RAKANGA}

O casco de tronco de árvore bũgu na língua geral amazônica, o nheengatu, é o meio de transporte fluvial mais antigo da Amazônia, o qual é utilizado por indígenas e caboclos, principalmente nas atividades de caça e pesca (CORDEIRO, 2020).

O casco é esculpido em um único tronco de árvore com uso de machado para cortar a árvore, facão para lapidar o tronco, formão e enxó para esculpir a parte interna da madeira. A partir desse processo surge o casco, uma embarcação que carrega em suas linhas habilmente entalhadas a população da Amazônia que habitam às margens de rios, lagos e igarapés da região desde o surgimento das primeiras populações ameríndias.

Segundo Németh (2011, p. 5), a canoa mais antiga que se tem notícia foi uma embarcação de pinheiro escavado, construída em Pesse na Holanda, entre os séculos 8.200 e 7.510 anos a.C. Ela mede quase 3 metros de comprimento, e $40 \mathrm{~cm}$ de largura (Figura 1). A canoa, que se encontra no Museu Drents, em Assen, Holanda, foi encontrada em 1955 durante a construção de uma estrada. 
Figura 1 - Canoa de Pesse

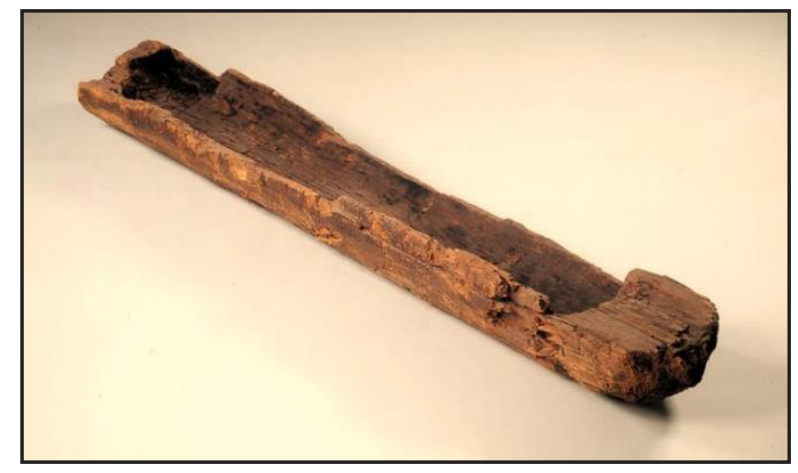

Fonte: Németh, 2011.

A canoa encontrada em Pesse, Holanda é muito semelhante ao casco de tronco de árvore bũgu construído na Amazônia pelos ameríndios desde as primeiras ocupações na região do vale amazônico, principalmente em seu formato. O casco de tronco de madeira construído por indígenas e caboclos da região amazônica também é feito a partir de um único tronco de árvore e, essa técnica e modo de construção de canoas (cascos) ainda é na atualidade praticada pelos indígenas e ribeirinhos por se de baixo custo, grande utilidade e de fácil deslocamento em lugares como cabeceira de rios e em ambientes de vegetação aquática. Geralmente, esse tipo de embarcação é a preferida dos pescadores e caçadores, devido à mobilidade e à manobrabilidade, que se pode realizar com essa embarcação em lugares de difícil acesso (Figura 2).

Figura 2 - bũgu (casco de tronco de árvore)

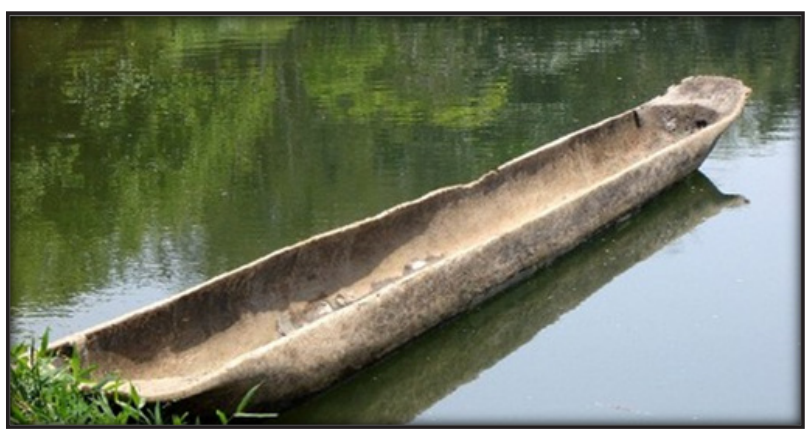

Fonte: Instituto Memória Brasil (IMB), 2017. 
Observa-se que os cascos (canoas) são de estruturas rústicas, e ambos são similares em seus designs. O casco da Figura 2, construído na Amazônia nos anos 80, é feito de tronco de castanheira bertholletia excelsa, uma árvore muito conhecida na região, e que produz um fruto chamado castanha, de grande valor econômico no mercado brasileiro. Acredita-se que o processo de construção das canoas tenha sido o mesmo, e que isso é uma prática milenar que vem desde que o homem precisou navegar e com isso, passou a construir barcos de troncos de árvores. A Amazônia, por ser uma região de grandes rios navegáveis, as canoas e barcos apresentam-se como meios de transportes mais viáveis.

O uso da canoa no continente americano foi citado no diário da primeira viagem de Cristóvão Colombo às Américas de 1492, no qual, dia 26 de outubro, pela primeira vez, ele escreveu a palavra canoa almadía, para definir especificamente um tipo de embarcação da região do continente:

Sábado, 13 de octubre. Luego que amaneció vinieron a la playa muchos de estos hombres, todos mancebos, como dicho tengo, y todos de buena estatura, gente muy hermosa: los cabellos no crespos, salvo corredios y gruesos, como sedas de caballo, y todos de la frente y cabeza muy ancha más que otra generación que hasta aquí haya visto, y los ojos muy hermosos y no pequeños, y ellos ninguno prieto, salvo de la color de los canarios, ni se debe esperar otra cosa, pues está Este Oeste con la isla de Hierro, en Canaria, bajo una línea. Las piernas muy derechas, todos a una mano, y no barriga, salvo muy bien hecha. Ellos vinieron a la nao con almadías, que son hechas del pie de un árbol, como un barco luengo, y todo de un pedazo, y labrado muy a maravilla, según la tierra, y grandes, en queen algunas venían cuarenta o cuarenta y cinco hombres, y otras más pequeñas, hasta haber de ellas en que venía un solo hombre. Remaban con una pala como de hornero, y anda a maravilla; y si se le trastorna, luego se echan todos a nadar y la enderezan y vacían con calabazas que traen ellos. (COLOMBO, 1492 apud NÉMETH, 2011).

Sábado, 13 de outubro ao alvorecer, muitos homens chegaram à praia, todos eram jovens e de boa estatura, pessoas muito bonitas, de cabelos lisos e grossos como de rabo de cavalo, e toda a testa e cabeça muito mais larga do que outra geração que eu vi até então. Os olhos muito bonitos e não tão pequenos (NÉMETH, 2011, tradução nossa).

Eles chegaram ao navio de canoas feitas de troncos de árvores, barcos compridos e todos feitos em uma só peça, e esculpidos maravilhosamente, nos quais 
chegaram quarenta ou quarenta e cinco homens, e outros em canoas menores. Eles remavam com uma pá (remo) que funciona maravilhosamente (NÉMETH, 2011).

Na narrativa de Colombo, em 1492, citado por NÉMETH, (2011) fica bem evidente que ele está se referindo às canoas (cascos) de troncos de madeiras construídos, cada canoa de um único tronco de árvore. Portanto, mais uma prova cabal de que esse tipo de transporte fluvial já vinha sendo utilizado a séculos pelos povos ameríndios, assim como a pala (remo), outro importante material de madeira que serve para mover a canoa, como afirmou Colombo (Figura 3).

Figura 3 - Apuguitá (remo)

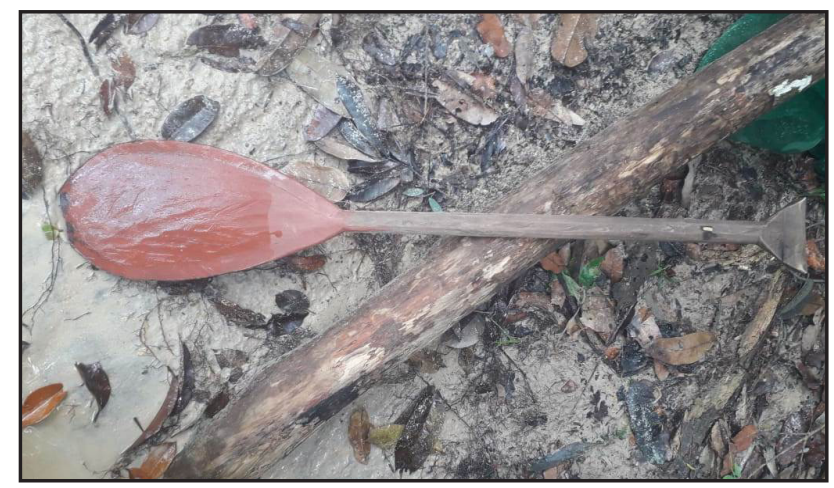

Fonte: Kim Puremanã, 2020.

O remo, apuguitá em Nheengatu é feito também de madeira, e é usado para mover e guiar a canoa em todas as direções. Esse material, na atualidade, ainda, é utilizado para tal fim, mas tem sido também objeto de decoração como artesanato indígena, assim como o casco que ainda é um dos meios de transporte fluvial muito utilizado na região por sua praticidade de locomoção e utilidade nas atividades de caça e pesca nos rios da Amazônia. A canoa e o remo são tão úteis aos povos amazônicos da zona ribeirinha para se locomoverem, assim como o carro é para a população urbana das grandes cidades.

A busca por meio de transportes, mais eficientes e adaptados ao meio em que estão inseridos, é uma necessidade das sociedades que, desenvolvem cada vez mais embarcações e veículos que facilitam seus deslocamentos, principalmente em grandes distâncias em que não seria viável ser feito a pé. Um 
dos elementos muito importante criado pelo homem foi a roda, em 3000 a.C., na Mesopotâmia. Esse material representou uma revolução no transporte mais eficaz, apesar de rudimentar e muito pesada. Assim, ao longo dos séculos, os seres humanos foram encontrando meios que facilitassem a locomoção e a navegação, de forma que um dos meios de transporte mais utilizados é o fluvial, principalmente pela capacidade de transportar grandes quantidades de carga em trajetos que não seria possível por meio de outro, principalmente de mercadorias (CARADINA, 2019).

\section{A RESSIGNIFICAÇÃO DAS EXPERIÊNCIAS SOCIOCULTURAIS}

Com a chegada dos ocidentais à Amazônia, ocorreram muitas mudanças, não só socioculturais e linguísticas como a introdução da kariwa nheenga (língua portuguesa), mas também no modo de transporte, que antes da chegada dos kariwa (homens brancos) era utilizado somente o bũgu, casco de tronco de árvore (Figura 4). Isso forçou a população indígena a uma ressignificação cultural e linguística ${ }^{5}$.

Figura 4 - Caso de tronco de árvore (bũgu)

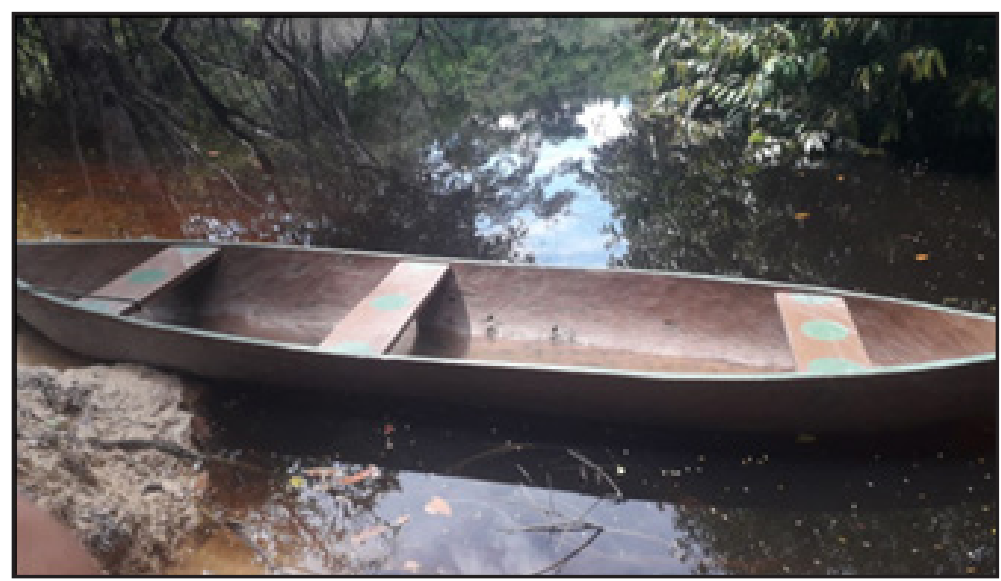

Fonte: Kim Puremanã, 2020.

5 A ressignificação cultural e linguística está diretamente relacionada as experiências que um indivíduo ou grupo passa a interagir em uma cultura e língua diferente da que eles estavam inseridos anteriormente (grifo nosso). 
Na Figura 4, observa-se como o processo de construção de canoa (casco) era feito de forma manual, entalhados com ferramentas como machado, facão, formão e enxó. Mas, com a chegada dos ocidentais na Amazônia foram introduzidas novas técnicas de conhecimentos de construção de embarcações por esses europeus aos povos amazônicos que aprenderam essas novas técnicas artífices de construção de canoas.

Caradina (2019, p. 2) reforça que, os meios de transportes evoluíram principalmente durante a Revolução Industrial, principalmente a partir de 1760, em que, a maioria das invenções que era restrita à Inglaterra, a partir da 2a Revolução Industrial (1850-1900) conquistou outros países se expandindo pela Europa, América e Ásia.

Desse modo, o processo de construção de embarcação fluvial na Amazônia, no decorrer do tempo passou também por diferentes fases e hoje há uma grande variedade de embarcações, tanto motorizadas e não motorizadas, assim como também para passageiros quanto para cargas. Como exemplo, pode-se citar a igara (canoa de tábuas) (Figura 5).

Figura 5 - Igara (canoa de tábua)

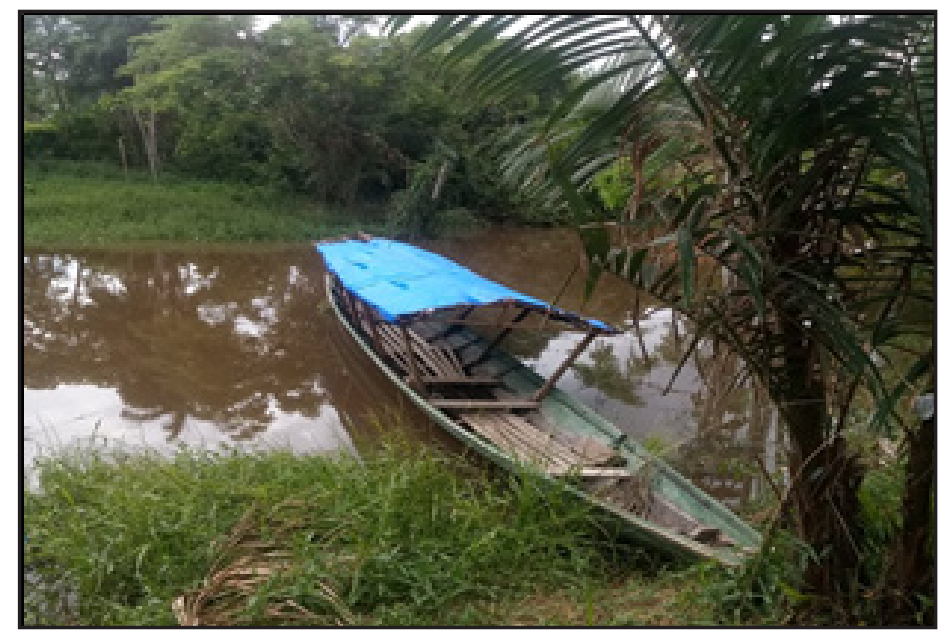

Fonte: Augusto Baniwa, 2020.

Observa-se que a canoa de tábuas, igara em Nheengatu, é uma embarcação artesanalmente bem trabalhada, agregados em sua estrutura: tábuas, caibros, 
vigas de madeiras, pregos, parafusos e estopas para vedar os espaços entre as madeiras, além de cobertura de lona para proteção de chuva e sol. Como se pode ver, é uma embarcação com design mais elaborado que o casco.

Há também uma variação de canoas em termos de tamanhos. Se for pequena chama-se igaramirim, se for grande igarasu. Esses dois termos: mirim (pequeno) e asu (grande) são sufixos adicionados nos finais de palavras. Esses dois sufixos também são utilizados na língua portuguesa brasileira. Trata-se de empréstimos linguísticos da língua geral amazônica, o nheengatu ao português. Como exemplo em português brasileiro, usa-se em palavras como: paraná-mirim, cantor mirim, clube mirim, capim mirim, paraná-açu, capim-açu, andá-açu, jiboiaçu, jacaré-açu.

Mas há também embarcações como igarité, barco de grande porte motorizado, e igaritéasu, navio de transporte de carga e de passageiros. Essas embarcações maiores são também muito utilizadas em viagens de longas distâncias e, até mesmo em viagens nacionais (Figuras 6 e 7).

Figura 6 - Igarité (barco)

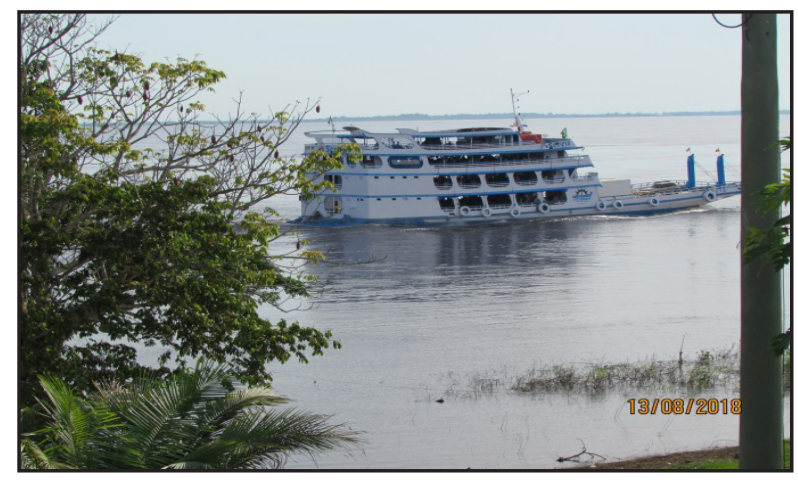

Fonte: Ademar Lima, 2020.

O barco igarité é uma embarcação motorizada e tem como principal função o transporte de passageiros e de cargas pelos rios da Amazônia. É uma embarcação que chega a transportar até mais de trezentas pessoas e mais de cinco mil toneladas de materiais em seu compartimento de cargas. Esse tipo de embarcação é usado exclusivamente em rios de água doce, não adentrando ao mar. Sua construção, até a década de 80 era feita também de madeira, mas atualmente há modelos construídos a partir de materiais como alumínio e ferro. 
Nas cidades da região amazônica, como Belém, Manaus, Acre, Santarém, Parintins e outras, o igarité ainda é o meio de transporte mais usados, principalmente pelas populações que residem ao longo dos rios da Amazônia, sendo em muitas cidades e vilas a única forma de locomoção das pessoas que precisam deslocarem-se entre essas localidades. O navio igaritéasu é uma embarcação de grande porte e bem maior que o igarité, o qual é utilizado preferencialmente em águas oceânicas (Figura 7).

Figura 7 - Igaritéasu (navio)

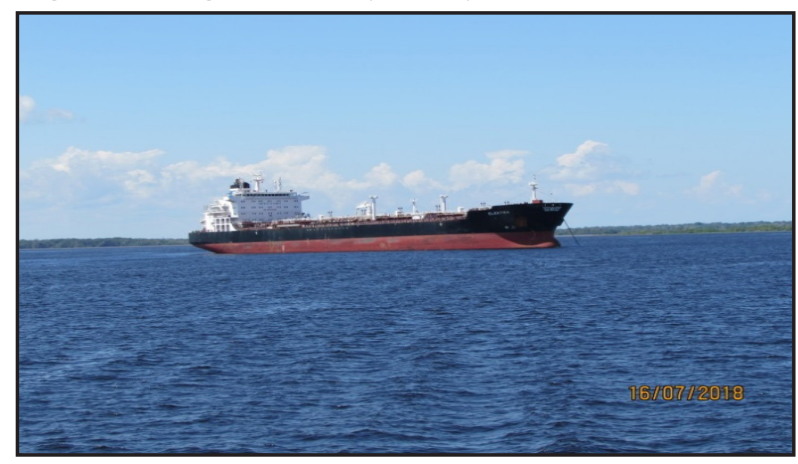

Fonte: Ademar Lima, 2020.

O navio igaritéasu é mais usado para transporte de grandes volumes de cargas como petróleo e gás, alimentos, materiais manufaturados, eletrônicos e eletrodomésticos. Mas também há modelos que são utilizados para transporte de pessoas, como os navios turísticos chamados de transatlânticos. Essas grandes embarcações marítimas são construídas a base de ferro fundido em siderúrgicas.

A construção de navios e de locomotivas mudou a forma com que a humanidade se locomovia e transportava seus produtos. Com a 3a Revolução Industrial que ocorreu em 1900, o mundo assistiu uma nova etapa evolutiva da história e muitas invenções foram aperfeiçoadas. Assim, surgiram as ferrovias e as vias férreas em várias regiões e cidades e, possibilitou a ligação de lugares distantes com os grandes centros urbanos da época. Nesse mesmo sentido ocorreu também a evolução do transporte marítimo com a construção de embarcações cada vez mais modernas (CARADINA, 2019).

Certamente, as tecnologias e o desenvolvimento industrial contribuíram de forma decisiva nos avanços das construções de embarcações fluviais e, atualmente, 
esses tipos de transportes tornaram-se os principais meios de locomoção dos povos que vivem na Amazônia.

\section{ANALOGIA: A RESSIGNIFICAÇÃO DOS TRONCOS ARBÓREOS E LINGUÍSTICOS}

Ao se falar de Amazônia, a primeira coisa que vem ao pensamento é de uma floresta cheia de árvores altaneiras e de espessuras colossais. É exatamente isso, dos elementos que compõem a flora amazônica, as árvores representam 50\% da composição do bioma amazônico com mais de 16 mil espécies arbóreas (STEEGE, 2013).

Outro elemento de grande abundância na Amazônia é a água, a qual é representada pelos rios, paranás, lagos, igarapés e igapós, elevando a região amazônica à categoria de maior bacia hidrográfica do mundo, a qual concentra 20\% da água doce do planeta (SOUZA, [s.d.]).

A Amazônia possui cerca de $80 \%$ das vias navegáveis, tornando-se assim a região com maior número de hidrovias do continente americano, de modo que, a população que vive na região amazônica tem como principal meio de transporte as embarcações, principalmente as construídas a partir de tronco de árvores, as quais são conhecidas na língua geral amazônica, o nheengatu como bũgu (casco) e igara (canoa).

Toda árvore passa por quatro estágios de desenvolvimento: nascimento, crescimento, reprodução e morte, assim como outros seres vivos, podendo ter um ciclo de vida de mais de mil anos, dependendo da espécie (CARVALHO, 2003).

No contexto cultural da Amazônia, a árvore que é escolhida para a construção de embarcação não deixa de existir, segundo a cultura indígena, ela transforma-se em uma yaka-yaka, que significa árvore que flutua, ou seja, em um bũgu ou igara (Figura 8). 
Figura 8 - Bũgu (casco de tronco de árvore)

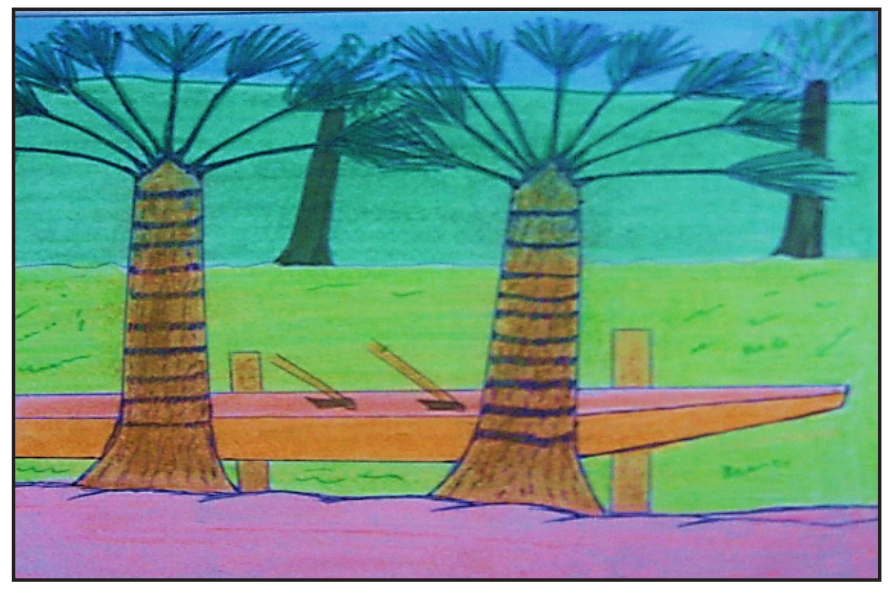

Fonte: Cordeiro, 2020.

Essa representação transcendental da árvore de sua forma autotrófica ${ }^{6}$ para a forma heterotrófica ${ }^{7}$ não é exclusivo da cultura ameríndia amazônica, nas literaturas de outros povos, encontramos muitas referências sobre esse assunto. Só nos textos do povo hebreu são dezenas de citações referentes às arbóreas como no texto da (ISAIAS, 44, 1) que afirma: "Todas as árvores do campo baterão palmas". Percebe-se nessa afirmação que as árvores deixam de ter somente a conotação de seres do reino autotróficos (plantas) passando à categoria de seres do reino heterotróficos (animais), ou seja, que tem movimento próprio (CAVALIER-SMITH, 1998).

Em outras culturas como a Maia, Escandinava, Chinesa, Maoris, Africana, a árvore faz parte também da tradição desses povos, onde há inúmeros simbolismos relacionados à árvore como: árvore da vida, árvore do conhecimento, árvore genealógica, árvore cósmica, árvore de Natal entre outras.

O processo de transcendentalidade está relacionado ao modo como a nossa mente constitui os objetos e torna possível a nós experimentá-los como objetos. Desse modo, o nosso sentimento permite-nos ajuizar o objeto de acordo com a

${ }^{6}$ Autotrófica refere-se ao ser vivo que é capaz de produzir seu próprio alimento, ou seja, capaz de produzir moléculas.

7 Diz-se do ser vivo que tem movimento próprio. 
conformidade final da representação junto à promoção da faculdade do conhecimento (KANT, 2005, p. 133).

Cenatti (2013, p. 18) afirma que "É pela dimensão da transcendência que o homem se projeta preparando e construindo o futuro". Ou seja, o homem é o resultado daquilo que ele vai construindo ao longo de sua existência como ser social. Assim, em conjunto com outros seres humanos, o homem interage por meio de suas capacidades e potencialidades socioculturais, linguísticas, políticas, psicológicas, filosóficas e religiosas.

Davies (2002) ressalta que o simbolismo não é arbitrário e tem uma propriedade baseada na sua significância histórica, assim como também de característica física. Para Wunenburguer (2002), a simbologia não está somente ligada a conteúdos perceptivos, mas se configura também como conteúdo idealizado a forma sensível e representada mentalmente.

Assim, a árvore está entre os símbolos que, em nível cultural proporcionam uma linguagem simbólica de âmbito universal, a partir de padrões facilmente decifráveis. Dessa forma, a árvore pode ser comparada como um arquétipo natura ${ }^{8}$ que não depende de estruturas socioculturais para o seu sentido (JUNG, 1995).

Como podemos observar, as árvores evocam inúmeros significados e representações relacionadas aos aspectos simbólicos do lugar, bem como aos aspectos emocionais dos sujeitos, a partir da capacidade de marcar, assim como de lembrar-se de momentos das vidas humanas deles representados simbolicamente (LEWIS, 1990).

$\mathrm{Na}$ área da linguagem, os linguistas usam constantemente árvores, troncos e galhos como metáforas para explicar e mapear as conexões entre troncos, grupos e famílias linguísticas, principalmente no processo de classificação. Entre os objetivos dessa classificação é mostrar como as línguas estão intimamente relacionadas e agrupadas em troncos e famílias linguísticas, por meio do grau de parentesco.

Dessa forma, na analogia da ressignificação dos troncos arbóreos e linguísticos, a partir da concepção dos povos indígenas amazônicos, a árvore como au-

8 Refere-se a conjuntos de imagens psicoides que dão sentido aos complexos mentais e às histórias passadas entre gerações, formando-se assim, o conhecimento e o imaginário do inconsciente coletivo (JUNG, 1995). 
totrófica (planta) deixa de existir, mas a partir da transformação de seu tronco em yaka-yaka (árvore que flutua), ela ressurge como uma bela canoa. Diferentemente da árvore, do tronco ou das famílias linguísticas indígenas que, quando deixam de existir desparecem para sempre.

Essas línguas indígenas dos povos da Amazônia têm sido extintas de forma tão rápidas que mais de $90 \%$ já desapareceram e, aproximadamente às 53 línguas indígenas vivas da região que ainda restam também estão em risco de desaparecer, e entre essas que foram extintas, estão as dos povos Baré, Mura e Warekena (Infográfico 1).

Infográfico 1 - Analogia das línguas em perigo e extintas
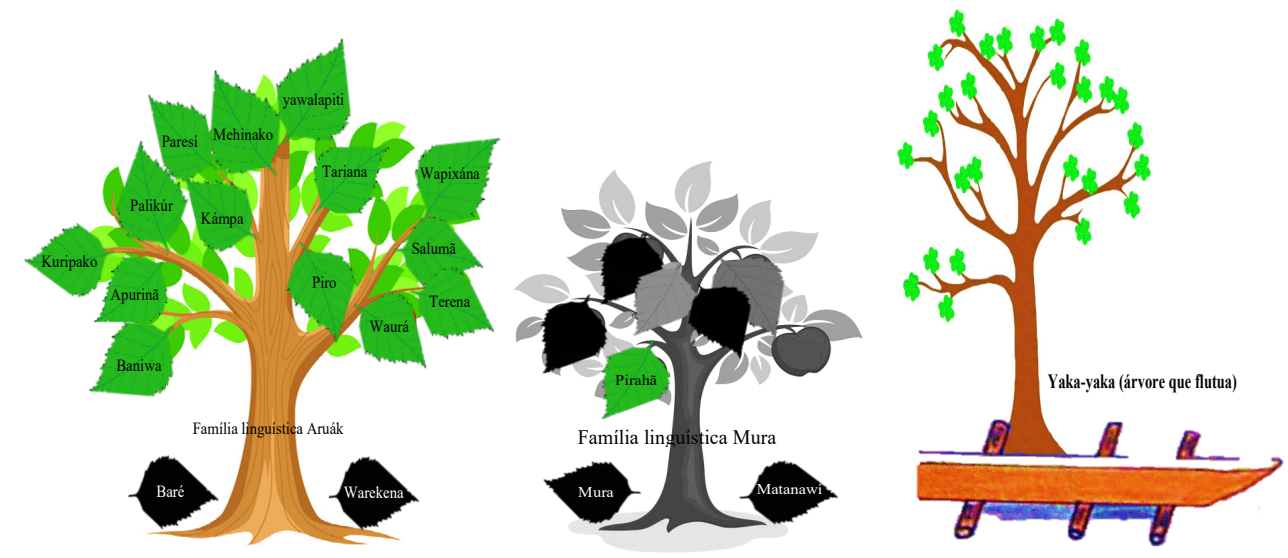

Fonte: Autoria própria, 2020.

Nessa breve analogia da ressignificação dos troncos arbóreos e linguísticos, apresentamos como se relacionam os troncos e famílias linguísticas. A árvore à esquerda simboliza a família linguística aruák, e suas folhas verdes representam as línguas ainda vivas, e as duas folhas pretas embaixo da árvore simbolizam as línguas baré e warekena que foram extintas. A árvore cinza no meio do Iconográfico simboliza a família linguística mura, e a folha verde simboliza a língua mura-pirahã. Embaixo da árvore, as duas folhas pretas ao chão simbolizam as línguas mura e matanawí que foram extintas. A árvore à direita 
do Iconográfico simboliza a yaka-yaka (árvore que flutua), que na concepção dos povos indígenas, mesmo depois de cortada, ela ressurge como uma bela canoa (bũgu).

Das mais de 16 línguas da família linguística aruák, restam apenas 14, as demais, como: baré, manáu, werekena foram extintas. Já os Mura que falavam as línguas mura, mura-pirahã (Pirarrã) e mura-matanawí, a partir do contato com os missionários jesuítas e carmelitas e a forte imposição da colonização portuguesa, tiveram 2 de suas línguas maternas extintas, mura e mura-matanawí. Na atualidade, somente a variedade mura-pirahã (Pirarrã) é falada por cerca de 200 indígenas Pirahã, atuais habitantes das cabeceiras do rio Marmelos e rio Maici, que segundo Nimuendaju (1946) pertence ao subgrupo Mura. Os pesquisadores Everett (1983) e Gonçalves (1990) descrevem o mura-pirahã como uma língua tonal, pois os significados são estabelecidos eminentemente a partir das relações dos tons. Através de assovios e gritos, os falantes pirahã são capazes de gerarem modalidades de comunicações específicas e bastante eficazes nas conversas, inclusive a longas distâncias.

Diferentemente da árvore autotrófica, que na concepção da cultura indígena amazônica, uma vez escolhida para construção de uma yaka-yaka, ela não morre, apenas passa por um processo de transformação e renasce como uma bela yaka-yaka (canoa que flutua), ganhando uma sobrevida como uma imponente canoa. Já as línguas indígenas não têm a mesma sorte, elas desaparecem para sempre, restando como alternativa aos povos indígenas que as falavam adotarem outras línguas para, assim, continuarem representando suas tradições, marcas identitárias e culturais, ou se assujeitar a cultura e língua do colonizador.

\section{CONSIDERAÇÕES FINAIS}

As tradições, culturas e línguas dos povos autóctones da Amazônia têm sido reprimidas e influências pela cultura ocidental desde o período da colonização na região amazônica. Esse processo continua, ainda, hoje com a desigualdade social e o desprestígio das culturas e línguas indígenas.

Não obstante, os povos indígenas estão tendo que ressignificar suas tradições, culturas e línguas, para sobreviverem diante da globalização, que toma conta e influencia todo o modo de vida dessas populações. 
Tomamos como exemplo, nesse estudo, os povos indígenas Baré, Mura e Warekena que sofreram com forte influência ocidental em suas culturas e, assim, perderem suas línguas maternas e tiveram que assimilar outras línguas, como o Nheengatu e o português. Nesse sentido, a analogia representada simbolicamente pelo tronco da árvore e o tronco linguístico se encaixa perfeitamente no contexto sociocultural e sociolinguístico desses povos.

Ficou evidente, na pesquisa, que os povos indígenas, de fato, não perderam suas essências identitárias e culturais. Entretanto, tiveram que as reconstruir para interagir com o novo modo de vida, que se apresenta nessa era globalizada. Assim, a árvore deixa de existir, mas ressurge como uma imponente canoa yaka-yaka que flutua sobre os rios e lagos da Amazônia.

Ao ressignificarem suas culturas e línguas, os povos indígenas potencializam e fortalecem seus modos de vidas socioculturais e sociolinguísticos no contexto amazônico. Desse modo, podemos afirmar que as asserções da pesquisa foram confirmadas, na medida em que os povos indígenas, ao terem suas culturas ameaçadas e perderem suas línguas maternas, se reinventaram a partir da ressignificação de suas culturas e assimilação de outras línguas, como o Nheengatu e o Português Brasileiro (PB), para que dessa forma pudesse interagir com a cultura mundo do ocidental.

Os povos indígenas vêm tentando manter a sobrevivência de suas línguas maternas, apesar que muitas etnias já perderam suas línguas nativas e tiveram que adotarem outra língua, como fizeram os Baré, os Mura e os Warekena ao adotarem o Nheengatu. De acordo com a Organização das Nações Unidas para a Educação, a Ciência e a Cultura (UNESCO), todas as línguas indígenas brasileiras estão em risco de extinção.

Portanto, urge a necessidade de se estudar e discutir este assunto, nos principais meios acadêmicos para se instigar o Estado a promover políticas culturais e linguísticas, que potencializem e viabilizem práticas de intervenção pedagógicas nas escolas e instituições que trabalham com ensino de línguas e cultura indígenas, para fortalecê-las no contexto sociocultural e sociolinguístico.

\section{REFERÊNCIAS}

BAGNO, Marcos. Dicionário de sociolinguística. São Paulo: Parábola, 2017. 
BANIWA, Augusto. Imagens de canoas do rio negro. 2020. 1 fotografia.

CARADINA, Gabriel. A evolução do transporte. São Paulo: Conjovem, 2019.

CARVALHO, Paulo Ernani Ramalho. Espécies arbóreas brasileiras. Brasília: Embrapa, 2003. v. 1

CAVALIER-SMITH, T. A revised six-kingdom system of life. London: Cambridge University Press, 1998.

CENATTI, Márcio José. Homem: ser de transcendência. São Paulo: Ixtlan, 2013.

COLOMBO, Cristovão. Diários de descoberta da América: as quatro viagens e o testamento. Tradução de Milton Persson. São Paulo: L\&PM Pocket, 1984.

CORDEIRO, Florêncio; LIMA, Ademar dos Santos; CRUZ, Aline; CASTRO, Ana Júlia Miranda; SOUSA, Rosineide Magalhães. Mayé yamunhã bũgu: uma abordagem sociolinguística sobre a origem do casco de madeira. Brasília: Cambridge Open Engage, 2020.

DAVIES, Douglas. The evocation symbolism of trees. In: COSGROVE, Denis; DANIELS, Stephen. (Ed.). The iconography of landscape: essays on the symbolic representation, design and use of past environments. Cambridge: University Press, 2002; p. 32-42.

GIL, Antônio Carlos. Métodos e técnicas de pesquisa social. 5. ed. São Paulo: Atlas, 2006.

HYMES, Dell. Foundations in sociolinguistics: an ethnographic approach. Philadelphia: University of Pennylvania Press, 1972.

IBGE. Panorama de Manaus. IBGE, [s.I.], [s.d.]. Disponível em: http://cod.ibge.gov.br/3WL. Acesso em: 29 out. 2020.

ISAIAS. Sagrada Bíblia Católica: Antigo e Novo Testamentos. Tradução de José Simão. São Paulo: Sociedade Bíblica de Aparecida, 2008. 1118 p.

JUNG, Carl Gustav. O homem e seus símbolos. Rio de Janeiro: Nova Fronteira, 1995.

KANT, Emmanuel. Crítica da faculdade do juízo. 2. ed. Rio de Janeiro: Forense Universitária, 2005.

LEWIS, Alice Carrol. Landscape in the Mind. In: RODBELL, Phillips D. (Ed.). Proceedings of fourth urban forestry conference. Missouri: The American Forest Association, 1990. 
NÉMETH, Peter Santos. O feitio da canoa caiçara de um só tronco: a cultura imaterial de uma nação, em 25 linhas. São Paulo: Instituto Costa Brasilis, 2011. (Dossiê)

PAIVA, Vera Lúcia Menezes de Oliveira. Manual de pesquisa em estudos linguísticos. São Paulo: Parábola, 2019.

PROFESSORES INDÍGENAS (P1; P2; P3; P4; P5). Gravação de conversas e narrativas. [jul. 2016]. Pesquisa de observação participante: Ademar dos Santos Lima. Manaus, 2018. 1 arquivo .mp3 (90 min.).

PUREMANÃ, Kim. Fotografias dos cascos do Tarumã Açú. 2020. 2 fotografias.

QUEIXALÓS, Fancesc; RENAULT-LESCURE, Odile. (Org.). As línguas amazônicas hoje. São Paulo: Instituto Socioambiental, 2000.

RODRIGUES, Aryon Dall'Igna. Línguas brasileiras: para o conhecimento das línguas indígenas. São Paulo: Edições Loyola, 2013.

SOUZA, Rafaela. Biomas brasileiros. Brasil Escola, [s.l.], [s.d.]. Disponível em: https:// brasilescola.uol.com.br/brasil/biomas-brasileiros.htm. Acesso em: 19 jul. 2020.

STEEGE, Hans ter; PITMAN, Nigel; SABATIER, Daniel. Hyperdominance in the Amazonian tree Flora. Science, Exeter, v. 342, n. 6156, p. 29, 2013

TARALLO, Fernando. A pesquisa sociolinguística. 7. ed. São Paulo: Ática, 2003.

WUNENBURGER, Jean-Jacques. La vie des images. Grenoble: Presses Universitaires de Grenoble, 2002.

\section{Sobre os autores:}

Ademar dos Santos Lima: Doutorando em Linguística pela Universidade de Brasília (UnB). Mestre em Letras e Artes pela Universidade do Estado do Amazonas (UEA). Licenciado em Letras/Língua e Literatura Inglesa pela Universidade Federal do Amazonas (UFAM). Professor de Nível Superior na Secretaria Municipal de Educação de Manaus. E-mail: ademarlima7@hotmail.com, ORCID: https://orcid.org/0000-0002-5091-1465

Rosineide Magalhães de Sousa: Pós-doutorado em Linguística Aplicada pela Universidade de Campinas. Doutora em Linguística pela Universidade de Brasília (UnB). Mestre em Linguística pela UnB. Graduada em Letras pela Universidade Católica de Brasília. Professora associada na Universidade de Brasília (UnB). Atua 
na Licenciatura em Educação do Campo, na área de linguagem, e na pós-graduação em Linguística. É líder do grupo de pesquisa (Socio) Linguística, Letramentos Múltiplos e Letramento, certificado pelo CNPq. E-mail: rosimaga@uol.com.br, ORCID: https://orcid.org/0000/0001-7588-4224

Recebido em: 17/09/2020

Aprovado para publicação em: 05/03/2021 